\title{
Mother's choice to provide breast milk and developmental outcome
}

\author{
R MORLEY, T J COLE, R POWELL, ${ }^{*}$ AND A LUCAS \\ MRC Dunn Nutrition Unit, Cambridge and *The Ryegate Centre, Sheffield
}

SUMMARY The association between a mother's choice to provide breast milk and her baby's developmental status at 18 months post term was investigated in 771 low birthweight infants from five centres. Babies whose mothers chose to provide milk had an 8 point advantage in mean Bayley mental developmental index over infants of mothers choosing not to do so. A $4 \cdot 3$ point advantage remained after adjusting for demographic and perinatal factors. A similar finding was derived using a fundamentally different and questionnaire based test (academic scale of Developmental Profile II). Whether this significant residual developmental advantage relates to parental factors or to a beneficial effect of human milk itself on brain development has important implications for the nutritional management of premature babies.

Later developmental status of children who were breast fed has been reported to be higher than in those fed artificially. ${ }^{1-4}$ These two groups, however, differ significantly in social, demographic, and educational factors that are known to be related to developmental scores. Silva et al,,$^{5}$ in a study where breast fed children were matched with non-breast fed controls, found no significant developmental advantage for those breast fed for varying lengths of time. Rodgers, ${ }^{6}$ analysing data from the National Survey of Health and Development (1946 cohort), found that after adjusting for social and demographic factors those children who had been entirely breast fed had a small, significant advantage on tests at 8 and 15 years. Using data from the Child Health and Education Study five-year follow up, Taylor and Wadsworth found a positive correlation between duration of breast feeding and performance in tests of vocabulary and visuomotor coordination, which persisted after similar adjustment. ${ }^{7}$

Low birthweight infants are a special population. They are a high risk group for impaired development. Moreover, if the mother chooses to breast feed she may have to express her milk, manually or mechanically, for a prolonged period until her infant is able to feed from the breast. A previous analysis of data from the cohort studied here has identified the factors independently related to a mother's choice to breast feed her low birthweight infant. ${ }^{8}$ In this study we have explored the relationship between the mother's intention to breast feed her preterm infant and the baby's developmental status at 18 months post term.

\section{Patients and methods}

Babies under $1850 \mathrm{~g}$ at birth, admitted to the special care baby units in Cambridge, Ipswich, Kings Lynn, Norwich, and Sheffield between January 1982 and March 1985, were entered into four parallel trials of preterm infant feeding, details of which are published elsewhere. ${ }^{9}$ Mothers chose whether or not they wanted to provide breast milk for their infant within 72 hours of delivery. In this study we have examined how this choice relates to development (though it should be emphasised that this is an epidemiological, non-random comparison and is not one of the randomised feeding trials cited above). Detailed information was collected on the family structure, social class, and mother's education level; and also on the pregnancy, labour, delivery, and the neonatal period.

Social class was coded using the Registrar General's classification based on the occupation of the income providing parent or on the father's occupation if both parents were earning, and with class 3 subdivided into non-manual and manual. Mother's education was coded as follows: $1=$ no educational attainments, $2=$ up to four passes for the certificate of secondary education (CSE), $3=$ any ' $O$ ' levels or more than four CSEs, $4=$ any ' $A$ ' levels, and 
$5=$ degree or higher professional qualifications. Birth rank was defined as the child's birth order in the surviving children of the family, with infants from multiple births assigned equal rank. Mode of delivery was categorised as caesarean or vaginal.

The 834 surviving infants were invited to an 18 month follow up examination. Infants from the four East Anglian centres were seen by RM; RP supervised follow up in Sheffield.

Two different tests of mental ability were administered: the Bayley mental scale ${ }^{10}$ and the academic scale of Developmental Profile II. ${ }^{11}$ The Bayley mental scale was scored on items presented to the child by the examiner, the mental developmental index being calculated from the raw score. A questionnaire to the care giver was used for the academic scale of Developmental Profile II, from which an IQ equivalent was calculated. The child's age from expected date of delivery (that is, chronological age minus the difference between date of delivery and term) was used in calculating the scores.

The Bayley mental scale, like most tests of mental ability in young children, requires age appropriate manipulative skills; therefore in children with cerebral palsy the score does not usually reflect the level of intellectual ability. At this age the academic scale of Developmental Profile II is based on items which are largely independent of fine manipulative skills. Results from 50 infants with cerebral palsy are therefore included in analyses of IQ equivalent, but not in analyses of the mental developmental index.

Of the 834 infants surviving to $\mathbf{1 8}$ months from expected date of delivery, the Bayley mental scale was successfully administered in 746 cases $(89 \%)$, the academic scale of Developmental Profile II in 758 cases $(91 \%)$, and one or both tests in 771 cases $(92 \%)$.

Student's $t$ test and multiple regression analysis were used for statistical analysis. Social class and mother's education were grouped to give a linear relationship with the mental developmental index and IQ equivalent (see footnote to table 2).

\section{Results}

Table 1 shows the mean scores at 18 months for the mental developmental index and IQ equivalent, both of which were significantly higher for the group of infants whose mothers chose to provide breast milk, with an advantage of 8 points in mental developmental index and 7 points in IQ equivalent.

From our previous analysis, factors independently related to the mother's decision to provide breast milk were mother's education level and age, baby's sex, birth rank (first child or not), and mode of delivery (caesarean versus vaginal), and whether the mother was a single parent. ${ }^{8}$ Other factors related (though not independently) to the mother's choice to provide breast milk and found from prior analyses to be significantly related to developmental scores were social class, gestation, and birth weight. The number of days for which the baby required ventilation was also taken into account here because the baby's illness might affect both feeding preference and the child's developmental outcome. All these factors were analysed for association with the mental developmental index and IQ equivalent, using multiple regression with the mental developmental index and IQ equivalent as dependent variables.

After adjustment for all these variables, a significant advantage of 4.3 points $(p<0.01)$ remained for babies whose mothers chose to provide breast milk. Mode of delivery and having a single parent mother were not associated with mental developmental index and when these two non-significant factors were removed from the model, the 4.3 point advantage (above) remained $(p<0.005)$. Table 2 shows the regression coefficients when only factors significantly related to outcome are included in the analysis. (The negative regression coefficient for gestational age in table 2 is due to the use of a birthweight cut off to select subjects for this study. All infants born after 34 weeks' gestation are small for gestational age; with birth weight in the equation the disadvantage of inappropriate birth weight for gestation becomes evident.)

Table 1 Mother's choice to provide breast milk and mean scores for Bayley mental developmental index and IQ equivalent at 18 months post term

\begin{tabular}{|c|c|c|c|c|}
\hline & \multicolumn{2}{|c|}{$\begin{array}{l}\text { Bayley mental } \\
\text { developmental index }\end{array}$} & \multicolumn{2}{|c|}{$\begin{array}{l}\text { IQ equivalent (from } \\
\text { Developmental Profile II) }\end{array}$} \\
\hline & $\begin{array}{l}\text { No of } \\
\text { babies }\end{array}$ & $\begin{array}{l}\text { Mean }(S E) \\
\text { score }\end{array}$ & $\begin{array}{l}\text { No of } \\
\text { babies }\end{array}$ & $\begin{array}{l}\text { Mean }(S E) \\
\text { score }\end{array}$ \\
\hline $\begin{array}{l}\text { Mother chose not to provide breast milk } \\
\text { Mother chose to provide breast milk }\end{array}$ & $\begin{array}{l}227 \\
469\end{array}$ & $\begin{array}{l}95 \cdot 4(1 \cdot 2) \\
103 \cdot 3(0 \cdot 9) \\
p<0.001\end{array}$ & $\begin{array}{l}245 \\
513\end{array}$ & $\begin{array}{l}101 \cdot 5(1 \cdot 1) \\
108 \cdot 3(0 \cdot 8) \\
p<0 \cdot 001\end{array}$ \\
\hline
\end{tabular}


1384 Morley, Cole, Powell, and Lucas

Table 2 Regression analysis including factors significantly associated with developmental scores at 18 months

\begin{tabular}{|c|c|c|}
\hline \multirow[t]{2}{*}{ Factor } & \multicolumn{2}{|c|}{ Bayley mental developmental index* } \\
\hline & $\begin{array}{l}\text { Regression } \\
\text { coefficient (SE) }\end{array}$ & p Value \\
\hline $\begin{array}{l}\text { Mother chose to provide } \\
\text { breast milk }\end{array}$ & $4 \cdot 3(1 \cdot 5)$ & $<0.005$ \\
\hline Social class $\dagger$ & $-4 \cdot 0(0.7)$ & $<0 \cdot 0001$ \\
\hline Days of ventilation & $-0.7(0.1)$ & $<0 \cdot 0001$ \\
\hline Female infant & $5 \cdot 1(1 \cdot 3)$ & $<0 \cdot 0005$ \\
\hline Gestational age (weeks) & $-1 \cdot 2(0 \cdot 3)$ & $<0 \cdot 0005$ \\
\hline Birth rank $\ddagger$ & $4 \cdot 2(1 \cdot 4)$ & $<0.005$ \\
\hline Birth weight (per $100 \mathrm{~g}$ ) & $0.7(0 \cdot 3)$ & $<0 \cdot 05$ \\
\hline Mother's education $\S$ & $6 \cdot 0(2 \cdot 7)$ & $<0.05$ \\
\hline Mother's age $>20$ years & $5 \cdot 8(2 \cdot 3)$ & $<0 \cdot 05$ \\
\hline
\end{tabular}

${ }^{*}$ Cases of cerebral palsy excluded.

†Social class was categorised as: social class 1 or 2 , social class 3 non-manual, social class 3 manual, or social class 4 or 5 .

$\ddagger$ Birth rank was categorised dichotomously as first child or subsequent child.

\$Mother's education level was categorised as: 1, degree or higher professional qualifications; 2 , all other levels.

A similar adviantage in IQ equivalent of 4.4 points $(p<0.005)$ was found after adjustment for the same factors.

\section{Discussion}

A low birthweight infant whose mother chose to provide breast milk had an 8 point advantage in Bayley mental scale score by 18 months, over one whose mother chose not to do so. It might be suggested that this advantage is explained by social and demographic influences. Even after adjusting for these, however, a greater than 4 point difference remained. It is interesting that the same advantage was found in IQ equivalent, a fundamentally different test. Our analysis (table 2) shows that this is similar to the advantage seen for being a first child, being female, or belonging to a higher social class category, when other factors are held constant.

In term infants, comparable studies have yielded conflicting results, ${ }^{5} 7$ though our findings are broadly in agreement with those of Rodgers ${ }^{6}$ and Taylor and Wadsworth. ${ }^{7}$ (Interestingly, Rodger's report on the 1946 birth cohort relates to a time when high social class was not strongly associated with breast feeding.) Low birthweight infants, however, are a special population. The baby's condition can cause considerable parental anxiety and disruption of family life. The mother's milk may have to be expressed until her baby is able to suck. It is likely, therefore, that mothers who breast feed term infants are a different group from those who provide milk for their preterm babies.
It is possible that our failure to 'adjust out' the advantage seen in babies whose mothers chose to provide breast milk was due to some extent to our failure to identify all relevant demographic factors, though a wide range of such factors were considered-the most important being social class and mother's education. This problem could have been compounded by unavoidable 'measurement error' in the determination of factors like social class.

Alternatively we have considered the possibility that fresh maternal milk might contain a factor or factors, hitherto unrecognised, which promote brain growth or maturation in the period of rapid growth preterm. Human milk contains a wide range of hormones and growth promoting factors, which have never been explored in relation to early neurological development.

Finally, it is possible that the advantage is related to the mother's decision to provide milk, rather than to the consumption of breast milk itself. For instance, her choice could be a reflection of her level of concern for the infant's welfare and perception of her maternal role, which would later influence her interest in stimulating and facilitating her baby's developmental progress. Thus a wish to provide breast milk could be seen as an aspect of 'parenting', that was at least partly independent of social class or educational status.

An important question from these data is whether staff in the neonatal unit should actively encourage? provision of mother's milk for preterm infants on the grounds that it might improve developmental outcome. Currently, there is controversy over the use of human milk, in the light of mounting evidence that it may not meet the special requirements of infants born preterm. Information on whether or not breast milk itself exerts a significant effect on brain development would be critical in this debate. Analysis of data from our cohort is being undertaken to provide further evidence concerning the possible neurodevelopmental effects of preterm milk; on present information, such effects cannot be dismissed.

If, however, the developmental advantage observed here was not due to nutritional factors, it is of note that this advantage could not be 'adjusted out' in a regression model which included social class and mother's educational status. In that case our findings would have implications for the design of research into preterm infant feeding. For example, in a non-randomised study comparing the effect of mothers' milk with another diet on later psychometric scores, adjustment for group differences in standard demographic and social factors would not be effective in eliminating confounding (nonnutritional) effects on the outcome response. 
Individual developmental scores at 18 months have limited predictive value for future mental ability, but group mean scores, as presented here, are likely to be more predictive. In a planned future study of this cohort, we will determine whether the early developmental advantage of infants whose mothers chose to provide milk persists, decreases, or even increases later in childhood.

We gratefully acknowledge the help and cooperation of the paediatricians in Cambridge, Ipswich, Kings Lynn, Norwich, and Sheffield, and Farley Health Products Limited for financial help.

\section{References}

${ }^{1}$ Hoefer C, Hardy MC. Later development of breast fed and artificially fed infants. JAMA 1929;92:615-9.

2 Rogerson BFC, Rogerson CH. Feeding in infancy and subsequent psychological difficulties. Journal of Mental Science 1939;85:1163-82.

${ }^{3}$ Broad B. The effects of infant feeding on speech quality. $N Z$ Med J 1972;76:28-31.
4 Taylor B. Breast versus bottle feeding. NZ Med J 1977;85: 235-8.

5 Silva PA, Buckfield P, Spears GF. Some maternal and child developmental characteristics associated with breast feeding: a report from the Dunedin multidisciplinary child development study. Aust Paediatr J 1978;14:265-8.

6 Rodgers B. Feeding in infancy and later ability and attainment: a longitudinal study. Dev Med Child Neurol 1978;20:421-6.

7 Taylor B, Wadsworth J. Breast feeding and child development at 5 years. Dev Med Child Neurol 1984;26:73-80.

8 Lucas A, Cole TJ, Morley R, et al. Factors associated with mother's choice to provide breast milk for a pre-term infant. Arch Dis Child 1988;63:48-52.

9 Lucas A, Gore SM, Cole TJ, et al. A multicentre trial on the feeding of low birthweight infants: effects of diet on early growth. Arch Dis Child 1984;59:722-30.

10 Bayley N. Bayley scales of infant development. New York: Psychological Corporation, 1969.

11 Alpern GD, Boll TJ, Shearer MS. Developmental profile II. Aspen, Colorado: Psychological Development Publications, 1980.

Correspondence to Dr R Morley, Dunn Nutritional Laboratory, Downhams Lane, Milton Road, Cambridge CB4 1XJ.

Accepted 28 April 1988 